\title{
Ersatzschale aus Tupferumverpackung
}

\section{Zusätzliche Schalen auf Instrumentensieben sind im OP oft Mangelware. Unser Autor verrät Ihnen einen einfachen Trick, wie Sie Ihre Ausstattung ohne zusätzliche Kosten aufrüsten können.}

Bei endoskopischen Eingriffen wie der Ureteroskopie oder offenen Operationen wie der antegraden Varikozelensklerosierung müssen häufig verschiedene Flüssigkeiten auf dem Instrumententisch vorgehalten werden. Hierzu gehören Spülflüssigkeit, Kontrastmittel oder Ringerlösung. Häufig ist auf Instrumentensieben jedoch nur eine Schale zu finden - zusätzliche Schalen sind oft Mangelware. Hier hilft ein einfacher Trick: Wird die Oberseite einer Tupferumverpackung aufbewahrt und umgedreht, kann diese problemlos als Schale benutzt werden ( 0 Abb. 1 ) - ohne zusätzliche Kosten.

\section{Dr. Andreas Wiedemann, Witten}

\section{Korrespondenz:}

Dr. Andreas Wiedemann Evangelisches Krankenhaus im Diakoniewerk Ruhr gGmbH Lehrstuhl für Geriatrie

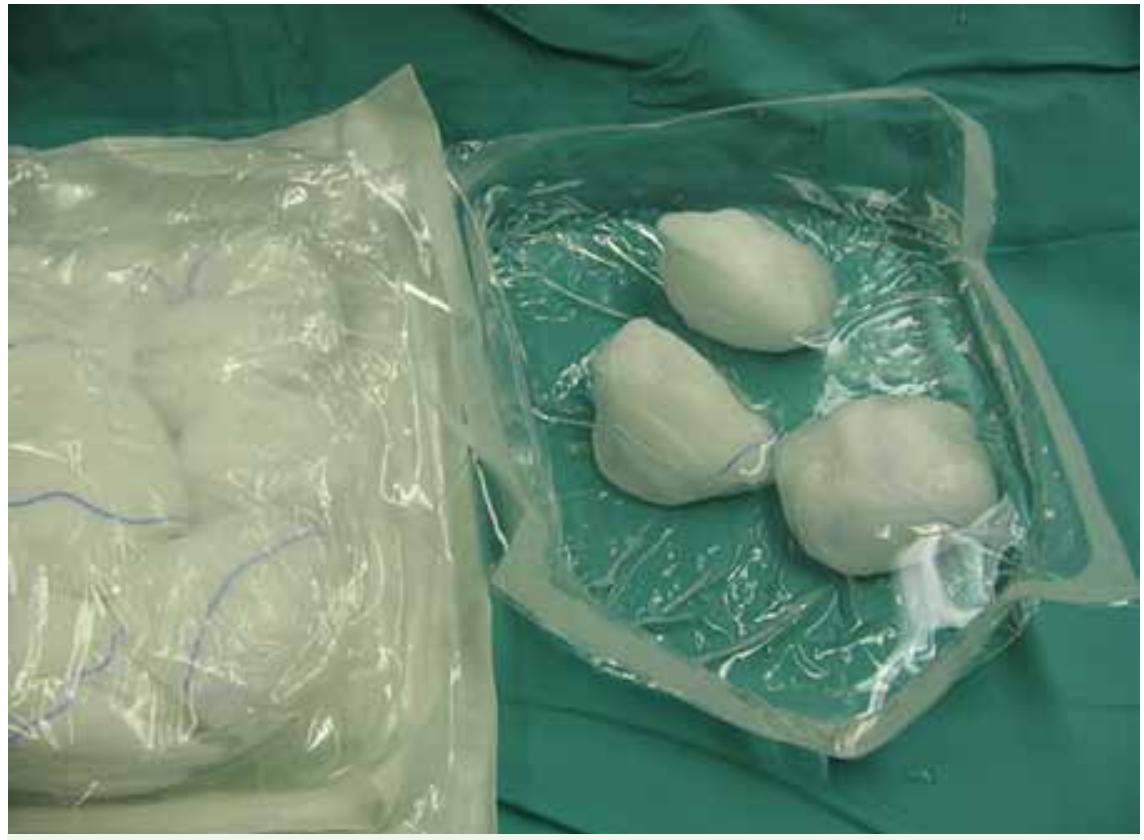

Abb.1 Umgedrehte Oberseite einer Tupferumverpackung als Schale im Gebrauch (rechts im Bild).

der Universität Witten/Herdecke

Pferdebachstr. 27

58455 Witten

Tel. 02302/175-2521

Fax. 02302/175-2075

awiedemann@diakonie-ruhr.de 